\title{
How common is attention deficit hyperactivity disorder (ADHD) in a cohort of children with functional constipation, and does ADHD treatment improve functional constipation?
}

\author{
Hassan Bazmamoun, Alireza Momeni, Leila Jahangard, Farzaneh Asnaashari, Nasrollah Pezeshki
}

Department of Pediatrics, Hamadan University of Medical Sciences, Hamadan, Iran

Submitted: 5 February 2019; Accepted: 19 August 2019

Online publication: 25 March 2021

Arch Med Sci 2023; 19 (2): 381-384

DOI: https://doi.org/10.5114/aoms/111841

Copyright (c) 2021 Termedia \& Banach

\section{Abstract}

Introduction: Attention deficit hyperactivity disorder (ADHD) is one of the most common neurodevelopmental disorders in children. Functional constipation is common in children and has a significant impact on the quality of their life, affecting both physical and emotional well-being. The aim of this study was to evaluate the frequency of ADHD in functional constipation patients and its treatment effect on constipation.

Material and methods: In this clinical trial study, 80 children with simultaneous ADHD and functional constipation were allocated to two equal groups by the block randomization method. One group was treated only with ADHD drugs and the second group was treated for ADHD and functional constipation. Subsequently, the treatment outcome was evaluated in both groups.

Results: The frequency of ADHD in functional constipation patients was $13.87 \%$. The frequency of functional constipation recovery in the first and second group was respectively $2(5 \%)$ and $39(97.5 \%)(p<0.001)$. ADHD treatment has no significant effect on the recovery of constipation. There was no statistically significant relationship between the response to treatment with age, sex and duration of having ADHD and constipation.

Conclusions: In patients with simultaneous ADHD and functional constipation, ADHD treatment did not influence the recovery of functional constipation and vice versa.

Key words: attention deficit hyperactivity disorder, constipation, children.

\section{Introduction}

Prevalence of constipation in the worldwide general population is very variable. It is estimated that between $0.7 \%$ and $29.6 \%$ of children suffer from constipation [1]. Functional constipation is constipation with no specific anatomical, medical or pharmaceutical causes, and is more common in children [2]. Functional constipation in children is multifactorial and two factors - inadequate dietary fiber intake and delayed bowel movements - often lead to progression of constipation [3]. Much effort has been made to standardize the terminology of children's constipation and several international guidelines have been accepted for its definition, including NASPGHAN [4], PACCT [5], and ROME III [6], but none of them have been widely used in clinical practice or research work. Attention deficit hyperactivity disorder (ADHD) is one of the common behavioral problems
Corresponding author: Nasrollah Pezeshki Department of Pediatrics Hamadan University of Medical Sciences Hamadan, Iran E-mail: nasrpezeshk@yahoo.com 
in children $[7,8]$. ADHD is defined as a sustained pattern of low attention or low attention with hyperactivity and impulsive behavior that is more than expected due to the age and level of development of the child [9]. The reported incidence of this disorder in school age children is between $3 \%$ and $8 \%[7,10,11]$. It is more common in males than females ( 3 in 1 to 5 in 1 ) and the symptoms of the disease usually present by 3 years old [7]. Children with ADHD are at increased risk of other problems such as antisocial behavior, anxiety disorders, mood disorders, learning disorders, drug abuse and communication problems [12-14].

Experts have experimentally found that in children's constipation, the importance of managing constipation-related behaviors is not less than that of a dietary or therapy regime [15].

Considering the higher prevalence of constipation and fecal incontinence among children with ADHD and the hypotheses explaining this relationship including behavioral problems, neurobiological disorders, defects in the relationship between the nervous system of the digestive system and the central nervous system, and the delay in maturation of the gastrointestinal tract [16], the aim of this study was to determine the frequency of $A D H D$ in children with functional constipation and the effect of ADHD treatment on their constipation.

\section{Material and methods}

In this study, 2,090 children aged 4 to 12 years with constipation referred to the pediatric gastroenterology clinic of Besat Hospital in Hamadan City, Iran, during the years 2016 and 2017, after confirmation of the diagnosis of functional constipation by a pediatric gastroenterologist (based on the criteria of 2006 ROME III [6]), were evaluated to determine simultaneous existence of ADHD using the Conners Questionnaire. If the patient had a total score of 34 points, he/ she was referred to a psychiatrist, and if ADHD was approved by a psychiatrist, he was entered into the study.

Patients with organic causes of constipation including Hirschsprung's disease, hypothyroidism, spina bifida occulta, anorectal abnormalities, non-retentive fecal incontinency, chronic intestinal pseudo-obstruction, history of anorectal/colon surgery, and taking medications which could modify bowel habit, were excluded from the study.

This study was conducted with the approval of the Ethics Committee of Hamadan University of Medical Sciences (with the ethics code, Deputy of Research and Technology IR.UMSHA. REC.1395.535). All parents gave written informed consent and the parents took the oral assent of the children.
Eighty patients out of 290 patients with simultaneous ADHD and functional constipation were selected by simple randomization and then randomly divided by random blocks into two equal groups.

Non-treated group: They were only treated for ADHD by a standard method [17].

Treated group: At the same time, they were treated for ADHD and functional constipation including a dietary regimen and PEG without electrolyte at a maximum dose $(0.7 \mathrm{~g} / \mathrm{kg} / \mathrm{day}$, 13.8-40.0 g/daily), twice a day. For children with rectal impaction, disimpaction was initially performed with bisacodyl suppositories for 3-5 days ( $5 \mathrm{mg} /$ daily $>4$ years). No further treatment was allowed for constipation during the study.

Patients' data were collected by a questionnaire including name, sex, age, duration of constipation, consistency/size/frequency of stool, number of painful defecations, fecal incontinence per week, and stool mass in the abdomen or rectum.

Parents were given dose regulation training to record the number and consistency of stools, frequency of stomach incontinence, abdominal pain, and pain relief.

Patients were examined and re-visited at 1, 3, 6 and 12 months after starting treatment, and drug dosage was adjusted.

To evaluate the response to treatment of ADHD, the Conners Questionnaire was used again, which would have been considered as improvement if the patient's score was less than 34.

The definition of response to constipation treatment was $\geq 3$ bowel movements weekly, $\leq 2$ episodes of fecal incontinence per month and absence of abdominal pain.

\section{Statistical analysis}

In this study, quantitative variables were presented as mean and standard deviation, and qualitative variables were reported as percentages. The $\chi^{2}$ test was used to evaluate the association between functional constipation improvement and sex/type of treatment. The Kolmogorov-Smirnov one sample test was used for normality detection. To compare disease duration between improved and non-improved patients, the Mann-Whitney $U$ test was used, because distribution of disease duration was not normal. Data were analyzed using SPSS16 software. $P$-value $<0.05$ was considered statistically significant.

\section{Results}

Eighty children with simultaneous ADHD and functional constipation were enrolled. Forty were in the non-treated group and forty in the treated group.

The percentage of male and female subjects in the non-treated group and treated group was respec- 
Table I. Comparison of demographic and clinical characteristic between treated and non-treated groups

\begin{tabular}{|lccc|}
\hline Variable & Non-treated group & Treated group $^{\mathrm{b}}$ & $\boldsymbol{P}_{\text {-value }}$ \\
\hline Male sex, $n(\%)$ & $22(55.0)$ & $23(57.5)$ & $0.822^{\star}$ \\
\hline Age [years], mean (SD) & $8.02(1.9)$ & $8.07(2.3)$ & $0.458^{* *}$ \\
\hline Duration of having constipation [months], mean (SD) & $11.52(2.89)$ & $11.37(2.78)$ & $0.594^{\star *}$ \\
\hline Duration of having ADHD [months], mean (SD) & $13.47(4.78)$ & $13.14(4.46)$ & $0.624^{\star *}$ \\
\hline
\end{tabular}

${ }^{\star} \chi^{2}$ test. ${ }^{*}$ Student's t-test. ${ }^{a}$ Patients only treated for ADHD. ${ }^{b}$ Patients treated for ADHD and constipation.

Table II. Comparison of demographic and clinical characteristics between recovered and non-recovered groups

\begin{tabular}{|lccc|}
\hline Variable & Recovered & Not recovered & $P$-value \\
\hline $\begin{array}{l}\text { Gender, } n(\%): \\
\text { Male }\end{array}$ & $24(60.0)$ & $27(67.5)$ & $0.485^{*}$ \\
\hline Female & $16(40.0)$ & $13(32.5)$ & $0.967^{* *}$ \\
\hline Age [years], mean (SD) & $8.04(2.1)$ & $8.06(2.03)$ & $13.61(4.80)$ \\
\hline $\begin{array}{l}\text { Duration of having ADHD [months], mean (SD) } \\
\text { mean (SD) }\end{array}$ & $13.00(4.50)$ & $11.61(2.88)$ & ${ }^{* *} 0.557^{* *}$ \\
\hline
\end{tabular}

${ }^{\star} \chi^{2}$ test. ${ }^{* *}$ Student's $t$-test.

tively $55 \%, 45 \%, 57.5 \%$ and $42.5 \%(p=0.822)$, with mean age $8.02 \pm 1.9$ and $8.07 \pm 2.3$ years $(p=0.458)$.

There were no significant differences regarding demographic data and duration of ADHD and constipation between the two groups (Table I).

The frequency of constipation recovery in the non-treated group was 5\% (2) while it was $97.5 \%$ (39) in the treated group; the difference was statistically significant $(p<0.001)$.

There was no statistically significant relationship between functional constipation recovery in children with ADHD and age, sex, and duration of having functional constipation and ADHD (Table II).

The frequency of ADHD recovery in the nontreated group and treated group was $100 \%$.

\section{Discussion}

In the present study, $13.87 \%$ of children with functional constipation had ADHD. The recovery of functional constipation in patients with ADHD who were simultaneously treated for constipation was higher than in patients who only received ADHD treatment. This means that treatment of ADHD has no effect on the treatment of constipation. There was no significant correlation between the recovery of functional constipation in children treated for ADHD and constipation with duration of having ADHD and functional constipation and patient' age and sex.

Also the treatment of constipation did not significantly affect the frequency of ADHD recovery.

In a study by McKeown et al. in the United States between 2005 and 2007 in children aged 4 to 12 years old, the prevalence of ADHD was
$4.4 \%$, and the incidence of functional constipation in children with ADHD was $4.1 \%$, while in children without ADHD it was $1.5 \%$. Based on the findings of this study, although the risk of ADHD may increase the risk of functional constipation, ADHD treatment has no significant effect on the increase or decrease of constipation [18].

In the present study, similar to McKeown et al.' findings, treatment of ADHD did not influence the functional constipation recovery.

In a study by Duel et al. in the United States whose results were published in 2003, in 28 patients with ADHD in comparison with 22 healthy persons with voiding dysfunction, measured by the Dysfunctional Voiding Symptom Survey (DVSS) questionnaire, the mean total score of the DVSS questionnaire in male subjects with ADHD and the control group was respectively $14.83 \pm 3.68$ and $6.6 \pm 5.74$, and in female subjects with $A D H D$ and the control group it was respectively $19.0 \pm 5.3$ and 5.83 . The results of this study showed that in patients with ADHD, the mean score of the DVSS questionnaire (symptoms of fecal dysfunction) was significantly higher than in the control group in both males and females [19].

According to the results of the Benninga et al. study on children aged 5 to 17 years, due to problems with defecation of stool and abdominal and behavioral problems, it seems there is no relationship between colonic/anorectal function and behavioral profiles. However, children with gastrointestinal disorders had more behavioral problems than the control group [20].

The results of research by Becker et al. on the neural process of excitement and fecal inconti- 
nence in 14 children with fecal incontinence and constipation showed that in children with fecal incontinence, the response process to emotions and excitement was increased and could be considered as neurocognitive vulnerability due to the relation of the enteric nervous system with the central nervous system [16].

In a study by Niemczyk et al. in children aged 7 to 17 years with ADHD, delayed bowel control was significantly more prevalent than in children in the control group but treatment of ADHD, especially medication, can improve the treatment outcome of incontinence [21], which is different from the findings of the present study.

In our study, the treatment of constipation did not significantly affect the frequency of ADHD recovery. Unfortunately, no similar study was found for comparison.

Although functional constipation may be more prevalent in children with ADHD [18], or children with gastrointestinal disorders may have more behavioral disorders and neurobiological disorders, including deficiencies in the nervous and central nervous system, and delayed maturation of gastrointestinal motility may have a relation with functional constipation [16], according to our research, the treatment of ADHD or constipation has no significant effect on the recovery of the other condition. On the contrary, each disorder requires separate treatment.

In conclusion, in patients with functional constipation, ADHD is a common association and treatment of $A D H D$ is not effective in the recovery of functional constipation. Also, treatment of constipation has no effect on the recovery of ADHD.

\section{Acknowledgments}

This article is a part of a pediatric medicine thesis supported by the Vice Chancellor for Research and Technology of Hamadan University of Medical Sciences (no. 9511267253). Thanks to the personnel of Besat Hospital and Hamadan Gastrointestinal Clinic who helped to collect the data.

\section{Conflict of interest}

The authors declare no conflict of interest.

\section{References}

1. Mugie SM, Benninga MA, Di Lorenzo C. Epidemiology of constipation in children and adults: a systematic review. Best Pract Res Clin Gastroenterol 2011; 25: 3-18.

2. Di Lorenzo C. Pediatric anorectal disorders. Gastroenterol Clin Notth Am 2001; 30: 269-87.

3. Rajindrajith S, Devanarayana NM. Constipation in children: novel insight into epidemiology, pathophysiology and management. J Neurogastroenterol Motil 2011; 17: 35-47.

4. Uc A, Hyman PE, Walker LS. Functional gastrointestinal disorders in African American children in primary care. J Pediatr Gastroenterol Nutr 2006; 42: 270-4.
5. Baker SS, Liptak GS, Colletti RB, et al. Constipation in infants and children: evaluation and treatment. A medical position statement of the North American Society for Pediatric Gastroenterology and Nutrition. J Pediatr Gastroenterol Nutr 1999; 29: 612-26.

6. Benninga M, Candy DC, Catto-Smith AG, et al. The Paris consensus on childhood constipation terminology (PACCT) group. J Pediatr Gastroenterol Nutr 2005; 40: 273-5.

7. Travis F, Grosswald S, Stixrud W. ADHD, brain functioning, and transcendental meditation practice. Mind Brain J Psychiatr 2011; 2: 73-81.

8. Wolraich M, Brown L, Brown RT, et al. ADHD: clinical practice guideline for the diagnosis, evaluation, and treatment of attention-deficit/hyperactivity disorder in children and adolescents. Pediatrics 2011; 128: 1007-22.

9. Sadock BJ, Sadock VA. Attention deficit disorder. In: Kaplan and Sadock's Synopsis of Psychiatry: Behavioral Sciences/Clinical Psychiatry. $10^{\text {th }}$ ed. Lippincott Williams \& Wilkins; Philadelphia 2007. 1206-17.

10. Grizenko N, Shayan YR, Polotskaia A, Ter-Stepanian M, Joober R. Relation of maternal stress during pregnancy to symptom severity and response to treatment in children with ADHD. J Psychiatry Neurosci 2008; 33: 10-6.

11. Linnet KM, Dalsgaard S, Obel C, et al. Maternal lifestyle factors in pregnancy risk of attention deficit hyperactivity disorder and associated behaviors: review of the current evidence. Am J Psychiatry 2003; 160: 1028-40.

12. Amiri S, Fakhari A, Golmirzaei J, Mohammadpoorasl A, Abdi S. Tourette's syndrome, chronic tics, and comorbid attention deficit/hyperactivity disorder in elementary students. Arch Iran Med 2012; 15: 76-8.

13. Faraone SV, Biederman J, Mennin D, Russell R, Tsuang MT. Familial subtypes of attention deficit hyperactivity disorder: a 4-year follow-up study of children from antisocial-ADHD families. J Child Psychol Psychiatry Allied Disciplines 1998; 39: 1045-53.

14. Dursun OB, Şengül F, Esin IS, Demirci T, Yücel N, Ömezli MM. Mind conduct disorders in children with poor oral hygiene habits and attention deficit hyperactivity disorder in children with excessive tooth decay. Arch Med Sci 2016; 12: 1279-85.

15. Di Lorenzo C. Childhood constipation: finally some hard data about hard stools! J Pediatr 2000; 136: 4-7.

16. Becker A, Rubly M, El Khatib D, Becker N, Von Gontard A. Central nervous system processing of emotions in children with faecal incontinence. Acta Paediatrica 2011; 100: e267-74.

17. Sadock BJ, Sadock VA, Ruiz P. Attention deficit/hyperactivity disorder. In: Kaplan and Sadock's synopsis of psychiatry: Behavioral sciences/clinical psychiatry. $11^{\text {st }}$ ed. Wolters Kluwer, Philadelphia 2015; 1169-80.

18. McKeown C, Hisle-Gorman E, Eide M, Gorman GH, Nylund $\mathrm{CM}$. Association of constipation and fecal incontinence with attention-deficit/hyperactivity disorder. Pediatrics 2013; 132: e1210-5.

19. Duel BP, Steinberg-Epstein R, Hill M, et al. A survey of voiding dysfunction in children with attention deficithyperactivity disorder. J Urol 2003; 170: 1521-4.

20. Benninga MA, Voskuijl WP, Akkerhuis GW, Taminiau JA, Büller HA. Colonic transit times and behaviour profiles in children with defecation disorders. Arch Dis Child 2004; 89: 13-6.

21. Niemczyk J, Equit M, Hoffmann L, von Gontard A. Incontinence in children with treated attention-deficit/hyperactivity disorder. J Pediatr Urol 2015; 11: 141.e1-6. 